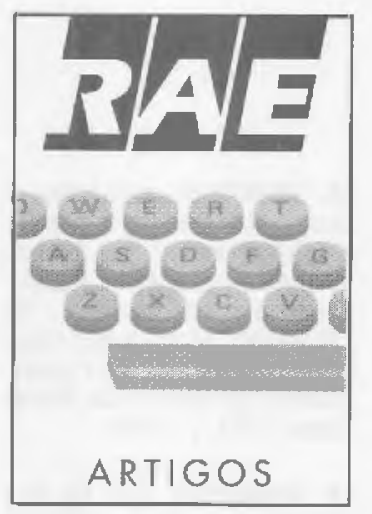

\title{
NBR 19000 X MANUFATURA: CONSIDERAÇÕES SOBRE SUA APLICAÇÃO VANTAGENS E DESVANTAGENS
}

As reais implicações e inter-relacionamento entre estratégia de manufatura e a adoção da ISO 9000.

The true relationships between manufacturing strategy and the adoption of ISO 9000 series.

PALAVRAS-CHAVE:

Estratégia competitiva, ISO

9000 , sistema da qualidade,

dimensōes competitivas, es

tratégia de manufatura.

\section{KEY WORDS:}

Competitive strategy, ISO 9000

quality system, competitive

dimensions, manufacturing strategy.

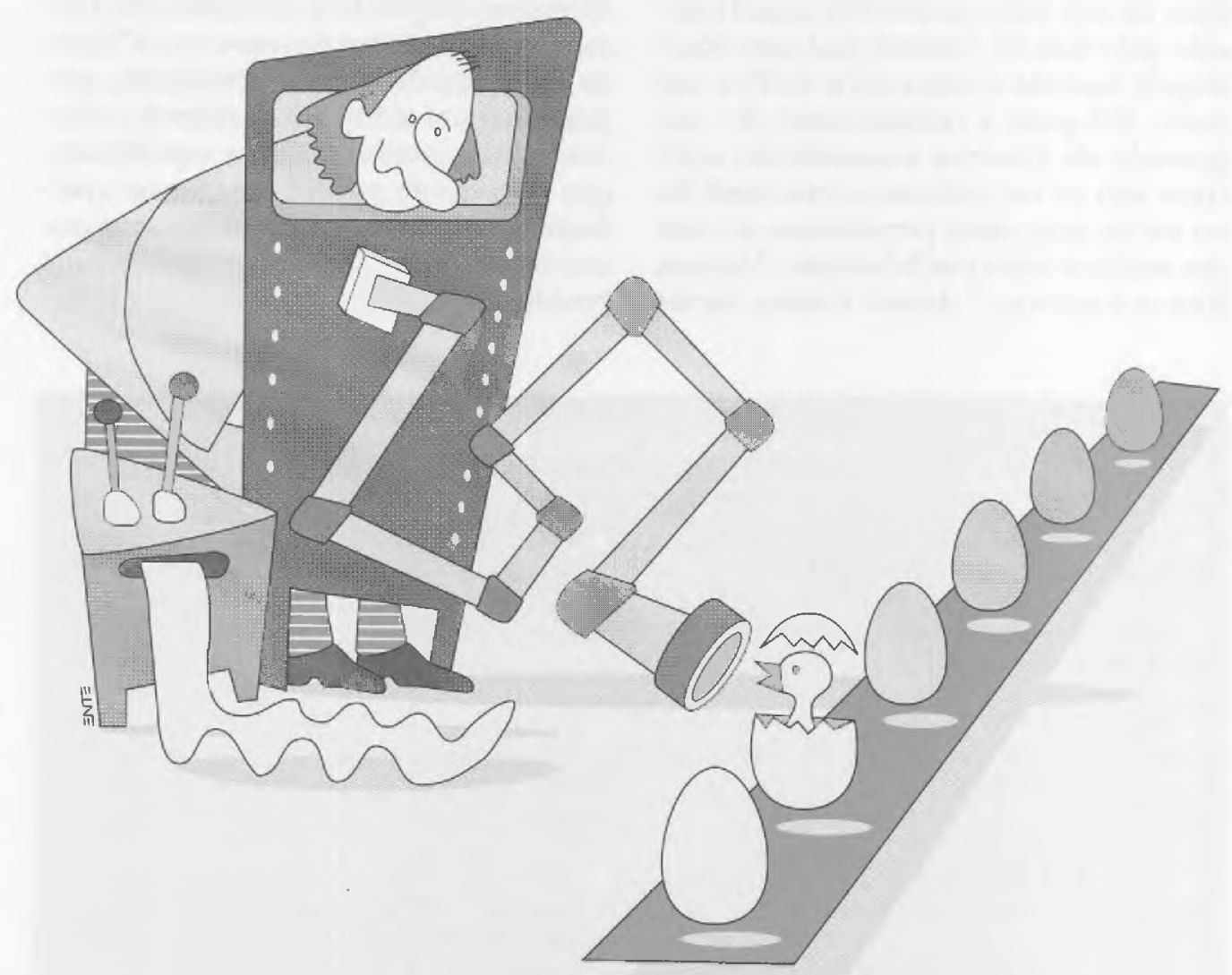

* Engenheiro, Mestre e Doutorando pela Escola Politécnica da USP, Consultor. 
Através da mídia, diariamente recebemos informaçōes acerca da crescente demanda do certificado de conformidade com as normas da série NBR 19000 (ISO 9000), ${ }^{1}$ por parte de empresas nacionais dos mais variados ramos de atividade.

Criadas pela International Standardization Organization - ISO, as normas da série ISO 9000 já são uma realidade nos países da CEE - Comunidade Européia, que decidiram em bloco pela sua adoção, no sentido de disciplinar a entrada de produtos em seu mercado.

Em alguns setores da economia européia (brinquedos, por exemplo), essas normas já vigoram há algum tempo, sendo que, em outras áreas importantes (máquinas, por exemplo), começaram a partir de janeiro deste ano.

En agosto de 1990, o Brasil, a exemplo de vários outros países fora da Comunidade Européia, também passou a adotálas, formando a série de normas NBR 19000.

Desde então, o governo, através das estatais, vem fomentando a elevação da competitividade da indústria nacional, exigindo que seus fornecedores atendam às recomendações das normas, fixando prazos e realizando auditorias.

A exemplo das estatais, através de acordos setoriais, alguns setores importantes da indústria privada, como a indústria automobilística, têm adotado postura semelhante, também porque sabem onde está a chave para o mercado internacional. Além dos negócios voltados aos mercados externos, notadamente o Mercosul e a Comunidade Européia, notamos movimentos bastante significativos por parte de empresas dos principais ramos industriais também em nível interno (Eletrobrás, Autolatina, GM, Fiat e outras), cujo foco é dirigido a exigir o certificado de conformidade por parte de seus fornecedores.

A implantação de procedimentos visando à conformidade com as normas da série ISO 9000, corresponde ao primeiro grande passo em direção à competitividade, pois traz consigo a necessidade de uma série de mudanças de comportamento e atitudes em relação à qualidade, inserindo na "cultura" das empresas variáveis de autoquestionamento, básicas para se implantar o conceito de "aper- feiçoamento contínuo" (Kaizen).

O certificado de conformidade ISO 9000 confere o reconhecimento formal, no sentido de atestar que o seu detentor segue normas, além de possuir um sistema de garantia da qualidade que lhe permite produzir bons produtos em processos estáveis e sob controle.

É necessário, no entanto, que sejam ponderados todos os fa-

tores que formam a capacidade competitiva das empresas, os mercados que exploram, os produtos oferecidos, para tornar claro todos os elementos vitais da empresa e suas reações previstas, em função da implantação de um sistema de qualidade como o recomendado e contido implicitamente na série NBR 19000.

Desse modo, este artigo tem como preocupação fundamental demonstrar que as implicações correspondentes à implementação de procedimentos de conformidade às normas da série NBR 19000 vão muito além da simples visão do atendimento a mais um fator qualificador de mercado. Assim sendo, procuraremos explorar um pouco mais seus efeitos na formação da capacidade competitiva da empresa, como resultado de uma estratégia de operações mais saudável e aplicada.

\section{CONSIDERAÇÕES SOBRE ESTRATÉGIA DA QUALIDADE}

Procurando proceder a uma redefinição conceitual de qualidade, envolvendo uma visão $\mathrm{com}$ perspectiva maís voltada para fora e atendendo aos anseios da alta gerência, cujos interesses são eminentemente estratégicos e competitivos, Garvin, ${ }^{2}$ baseado em um relatório da American Society for Quality Control -
1. ASSOCIAÇÃO BRASILEIRA DE NORMAS TÉCNICAS, Narmas de Gestão da Qualidade e Garantia da Qualidade Diretrizes para Seleçāo e Uso - NBR 19000, Ría de Janeiro 1990; Sistemas de Qualidade Modelo para Garantia da Qualidade em Projetos/Desenvolvimento, Produçăo, Instalação e Assistência Técnica NBR 19001, Río de Janeiro. 1990.

2. GARVIN, D.A. Competing on the eight dimensions of quality. Harvard Business Review, Boston, p. 101-9, Nov./Dec., 1987: What does "product quality" really mean? Sloan Management Review, p. 25-43, Fall 1984; Gerenciando a qualidade uma visão estratégica e competitiva. Rio de Janeiro: Qualitymark, 1992. 
3. SCHOEFFLER, S. et al. Impact of strategic planning on profits performance. Harvard Business Review, Boston, p. 137-45, Mar./Apr. 1974; BUZZEL, R. D., WIERSEMA, F. Succesful sharebuilding strategies. Harvard Business Review, Boston, p. 135-44, Jan./Feb. 1981; DEMING, W. E. Quality, productivity and competitive position. Cambridge: Center for Advanced Engineering Study, Massachussets, 1982; FEIGENBAUM, A. V. Quality and productivity. Quality Progress, p. 18-21, Nov. 1977

4. GARVIN, D. A. Op. cit. 1992, Cap. 6.
ASQC, apresenta uma definição sob o ponto de vista do cliente:

- não são os fornecedores do produto, mas aqueles para quem eles servem - os clientes, usuários e aqueles que os influenciam ou representam - que têm a última palavra quanto a até que ponto um produto atende às suas necessidades e satisfaz suas expectativas;

- a satisfação relaciona-se com o que a concorrência oferece;

- a satisfação, relacionada com o que a concorrência oferece, é conseguida durante a vida útil do produto, e não apenas na ocasião da compra;

- é preciso um conjunto de atributos para proporcionar o máximo de satisfação àqueles a quem o produto atende.

Deve-se atentar para o fato de que a qualidade foi definida aqui comparativamente - em relação aos concorrentes - e não em relação a padrões fixos, internos.

São os clientes, e não os departamentos internos, que dão a última palavra na determinação da aceitabilidade ou não de um produto.

A implicação disso é que o atendimento às especificações passou a ter ênfase menor, tornando-se prioritário a pós a cuidadosa definição das necessidades dos usuários. Se assim não fosse, a excelência do controle de processo traria pouca vantagem, pois seria facilmente desviada.

Essa perspectiva sugere várias exigências novas. A pesquisa de mercado para se avaliar a qualidade torna-se mais importante, caso contrário as empresas não teriam meios de saber como posicionar seus produtos com base na qualidade.

Existe a noção de que os consumidores de hoje são mais sensíveis às diferenças de qualidade e, provavelmente, capazes de dirigir suas compras de acordo com isso.

Por exemplo, espera-se que a qualidade leve a uma maior lealdade dos clientes, o que significa dizer que, com o tempo, isso se deve traduzir numa maior volta dos consumidores à compra do produto.

Pesquisas publicadas pela primeira vez nos anos 70 confirmaram o impacto da qualidade nos níveis mínimos de retorno. Por exemplo, os estudos do impacto sobre o lucro das estratégias de Marketing (Profit Impact of Marketing Strategies - PIMS), mostraram, não só que as empresas cujos produtos eram de qualidade superior tinham um retorno maior sobre o investimento - ROI, qualquer que fosse a participação no mercado, como também tais fatos ocorriam associados a ganhos de participação no mercado. ${ }^{3}$

Este e outros indícios convenceram muitos gerentes que a melhoria da qualidade poderia ser uma meta rentável.

Um exame do lado da produção também apontava nessa direção. Há muito tempo que os gerentes conhecem os custos da qualidade, mas só recentemente é que descobriram a existência de uma correlação positiva entre qualidade e produtividade.

Um processo de fabricação sem defeitos é muito mais eficiente do que outro que seja sempre interrompido para retrabalhos e para reparos. ${ }^{4}$ A utilizaçâo das máquinas será provavelmente maior, os estoques de segurança serão menores e a mão-de-obra será mais produtiva.

Adicionalmente, ao longo do tempo, com o avanço exponencial de algumas tecnologias (como a eletrônica, por exemplo), as empresas têm adquirido uma

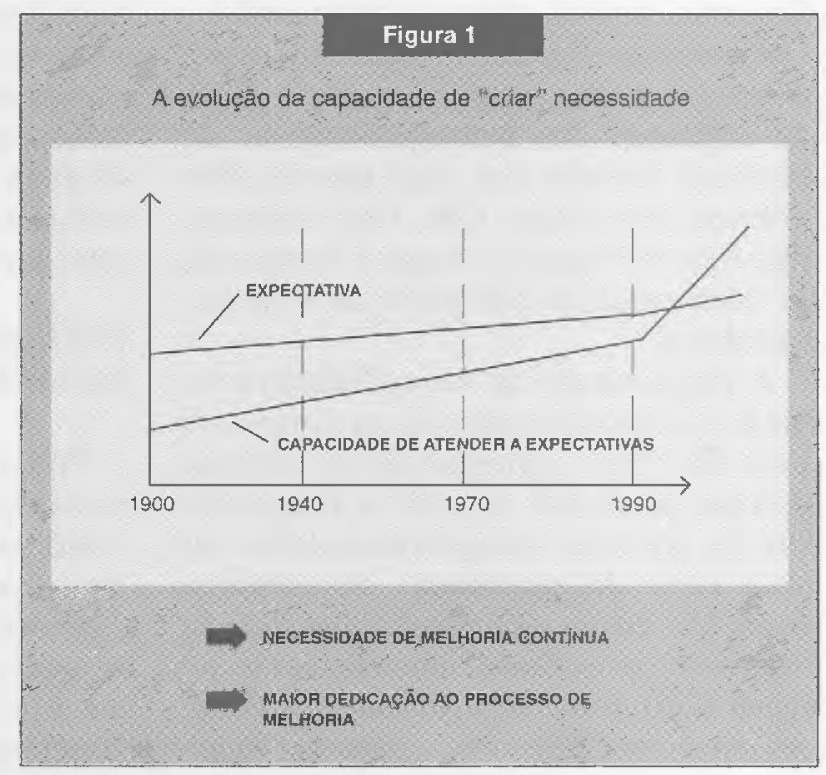


capacidade cada vez maior de atender às expectativas do mercado (ver figura 1).

Como resultado da acumulação de um formidável potencial criativo, favorecido e "alavancado" (leverage) por tecnologias cada vez mais sofisticadas, podemos afirmar (com a devida vênia dos especialistas em Marketing) que as empresas possuem (e usam) um grande poder de "criar" expectativas.

O resultado tem sido uma demanda cada vez maior de novos produtos, de encurtamento do "prazo admissível" para novos lançamentos, culminando na brutal redução que verificamos nos ciclos de vida dos produtos.

Diante das evidências, um número cada vez maior de empresas tem chegado às mesmas conclusões: a qualidade representa de fato uma poderosa arma na concorrência, oferecendo grandes benefícios, tanto do lado do mercado (concorrência), como do lado do custo (resultado da eficiência técnica).

Os gerentes mais dinâmicos perceberam isso rapidamente e logo deram mais um passo (e a concorrência também).

Se a qualidade estava associada tão de perto à rentabilidade, eles não viam razão alguma para não só se equiparar aos níveis de qualidade dos concorrentes, mas ultrapassá-los.

Como os concorrentes provavelmente não ficariam (como em geral não ficaram) de braços cruzados, as metas de qualidade se tornaram, então, alvos móveis, passíveis de reformulação contínua em níveis cada vez mais altos. O objetivo, portanto, passou a ser a melhoria

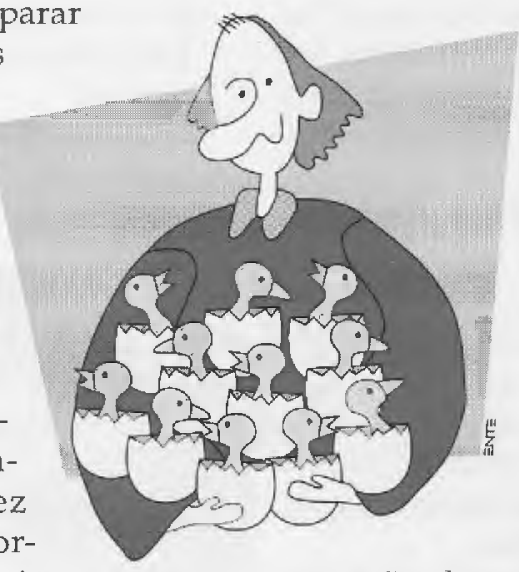
contínua, em vez de níveis médios de qualidade aceitáveis (Acceptable Quality Level - AQL). Isto por sua vez, passou a exigir uma dedicação ao processo de meIhoria, bem como o compromisso de toda a empresa.

É preciso haver uma compreensão mais ampla para obtenção de todos os benefícios, explorando todas as possibilidades "embarcadas" em um processo de melhoria.

Diversas empresas têm perdido muito

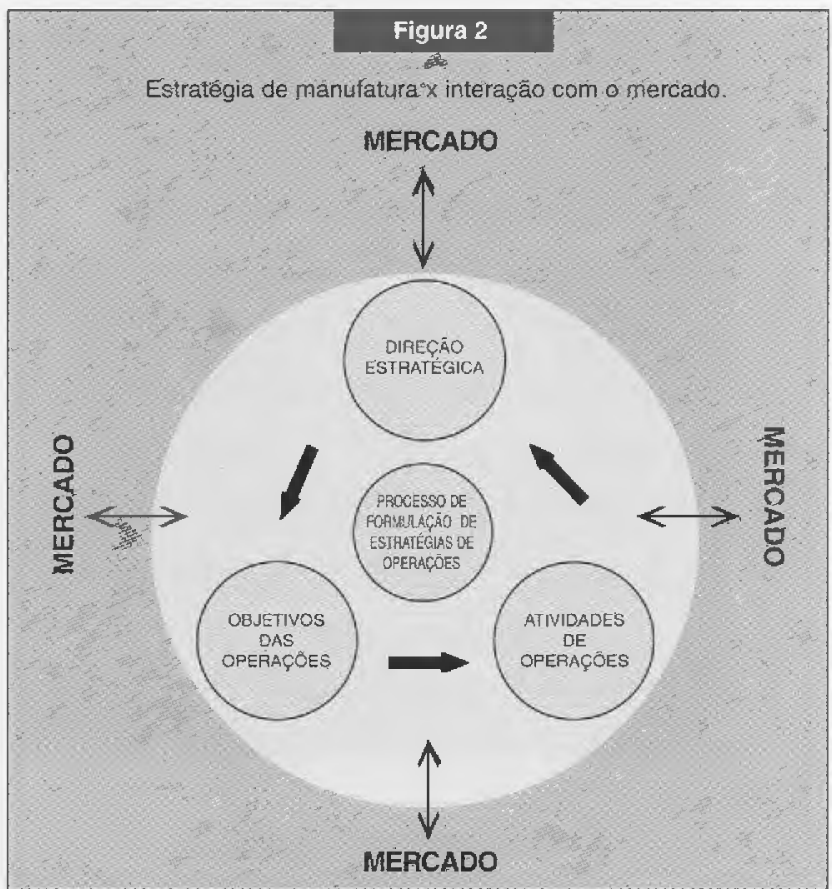

do potencial envolvido, com atuação bastante eficiente em treinamento das técnicas de controle da qualidade, mas sem conseguir ressaltar a relação entre qualidade e os objetivos básicos da empresa.

Os programas resultantes repisam muito a técnica, mas são pobres em motivação e finalidade.

O pensamento estratégico da qualidade também traz novas exigências e novos questionamentos aos profissionais da área. A especialização técnica continua sendo desejável, mas passa a ser mais importante uma compreensão dos objetivos estratégicos da empresa.

A gestão estratégica da qualidade é mais uma extensão de suas antecessoras do que uma negação delas, ou seja, é mais ampla, mais intimamente ligada à lucratividade e aos objetivos empresariais básicos, mais sensível às necessidades da concorrência e ao ponto de vista do consumidor, sendo também mais firmemente associada à melhoria contínua.

Tal conclusão é muito importante quando se fala em importação de modelos de 
5. SLACK, N. Vantagem competitiva em manufatura. Sảo Paulo: Atlas, 1993.

\section{A gestão estratégica da} qualidade é mais intimamente ligada à lucratividade e aos objetivos empresariais básicos, mais sensível às necessidades da concorrência e ao ponto de vista do consumidor, sendo também mais firmemente associada à melhoria contínua.

gestão "prontos" e acabados.

Com a ISO 9000 acontece a mesma coisa. As pessoas pensam apenas na dimensão mercadológica, no atendimento a uma condicionante (qualificadora) concorrencial de mercado, esquecendo-se de uma parte muito importante, que é o como a internalização dos procedimentos correspondentes à conformidade com a norma pode atuar como alavanca da capacidade do sistema de operações, no suporte à estratégia competitiva da empresa.

\section{ASPECTOS ESTRATÉGICOS DA MANUFATURA}

Como resultado da evolução dinâmica de contexto, as empresas passaram a adotar filosofias de negócios customerdriven, onde os clientes "puxam" todo o processo e determinam as características "fisionômicas" dos negócios.

Uma empresa deve perseguir, portanto, dois importantes desafios básicos, que sāo satisfazer melhor os clientes e ser melhor do que a concorrência.

Isso implica em trazer para dentro da fábrica, como sugerem as figuras 2 e 3 (que é onde tudo acontece), a visão dos clientes com os aspectos da compctitividade que são importantes para eles, além da visão dos concorrentes, ou seja, a medida contra a qual o seu próprio desempenho será julgado ${ }^{5}$ (ver figuras 2 e 3 ).

Para tanto, é necessário que a empresa utilize uma visão perspectiva, para compreender o contexto e saber "onde" o mercado realmente está, além de uma visão prospectiva que permita saber para onde isso tudo está caminhando, como evolui, novas forças, ou mesmo, paradigmas competitivos em formação.

Ao final, significa estabelecer de maneira dirigida as prioridades para aperfeiçoamento das operações.

A meta passa a ser, então, desenvolver uma operação de manufatura que possa dar à empresa uma vantagem competitiva em seu mercado.

Basicamente, podemos dizer que a estratégia de manufatura tem influência direta em:

- obtenção de produtos sem erro;

- entregas rápidas ao consumidor;

- cumprimento dos prazos prometidos de entrega;

- introdução de novos produtos em prazos adequados;

- operação em uma faixa de produtos larga o suficiente para satisfazer o desejo dos clientes;

- habilidade em mudar quantidades ou datas de entrega, conforme demandado pelo mercado;

- habilidade em produzir a custo compatível.

As implicações desse poder de influen-

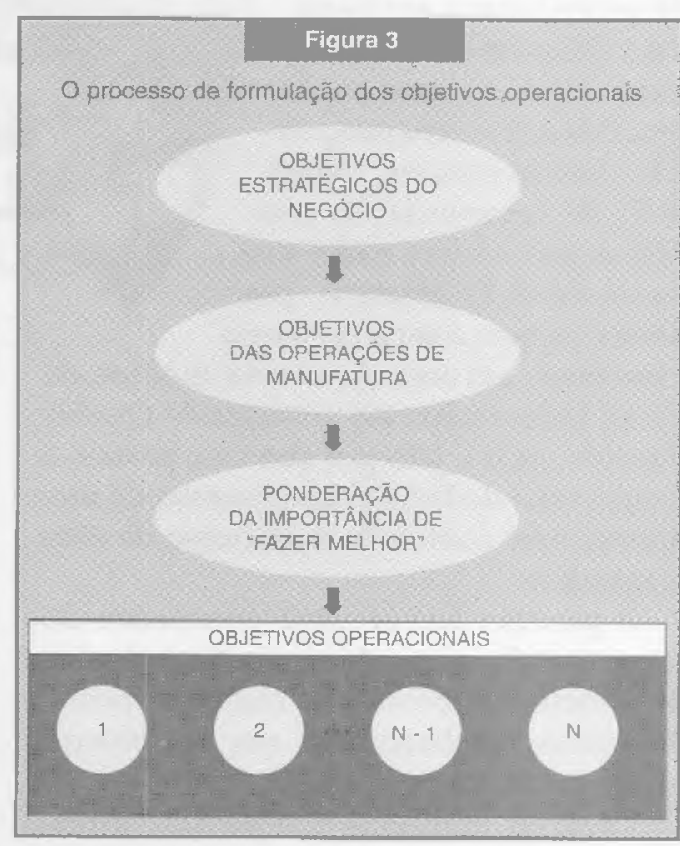

RAE - v. $34 \cdot$ - n. 4 - Jul./Ago. 1994 
ciar a maneira como as coisas são obtidas, é mais ou menos clara:

- a manufatura é a função central na provisāo da competitividade. Não é a funçăo dominante, mas o motor competitivo da empresa;

- a organização deveria ter uma expectativa bastante elevada quanto ao papel da manufatura, em termos do seu desempenho esperado, além de sua contribuição esperada ao debate estratégico;

- a empresa deve almejar uma posição na qual ela seja melhor do que seus concorrentes em tudo o que for importante, não só fazendo as coisas melhor do que a concorrência, mas também acreditando que é a única forma de garantir a sobrevivência competitiva a longo prazo.

Fazer melhor as coisas, no entanto, deve ser encarado como sendo o resultado direto da performance do sistema de manufatura adotado, um conceito que pode ser pensado como um composto formado por várias dimensōes: ${ }^{6}$ qualidade, velocidade, confiabilidade de entrega, flexibilidade e custo (ver figura 4).

Dentro de qualquer sistema de manufatura podemos utilizar estes cinco grandes objetivos (ou dimensões) definidos para "fazer melhor as coisas", considerando que desempenho global é igual a desempenho interno "mais" desempenho externo (ver figura 5).

6. Idem, ibidem.

Figura 4

Os cinco grandes objetivos ou dimensöes de um sistema de manufatura

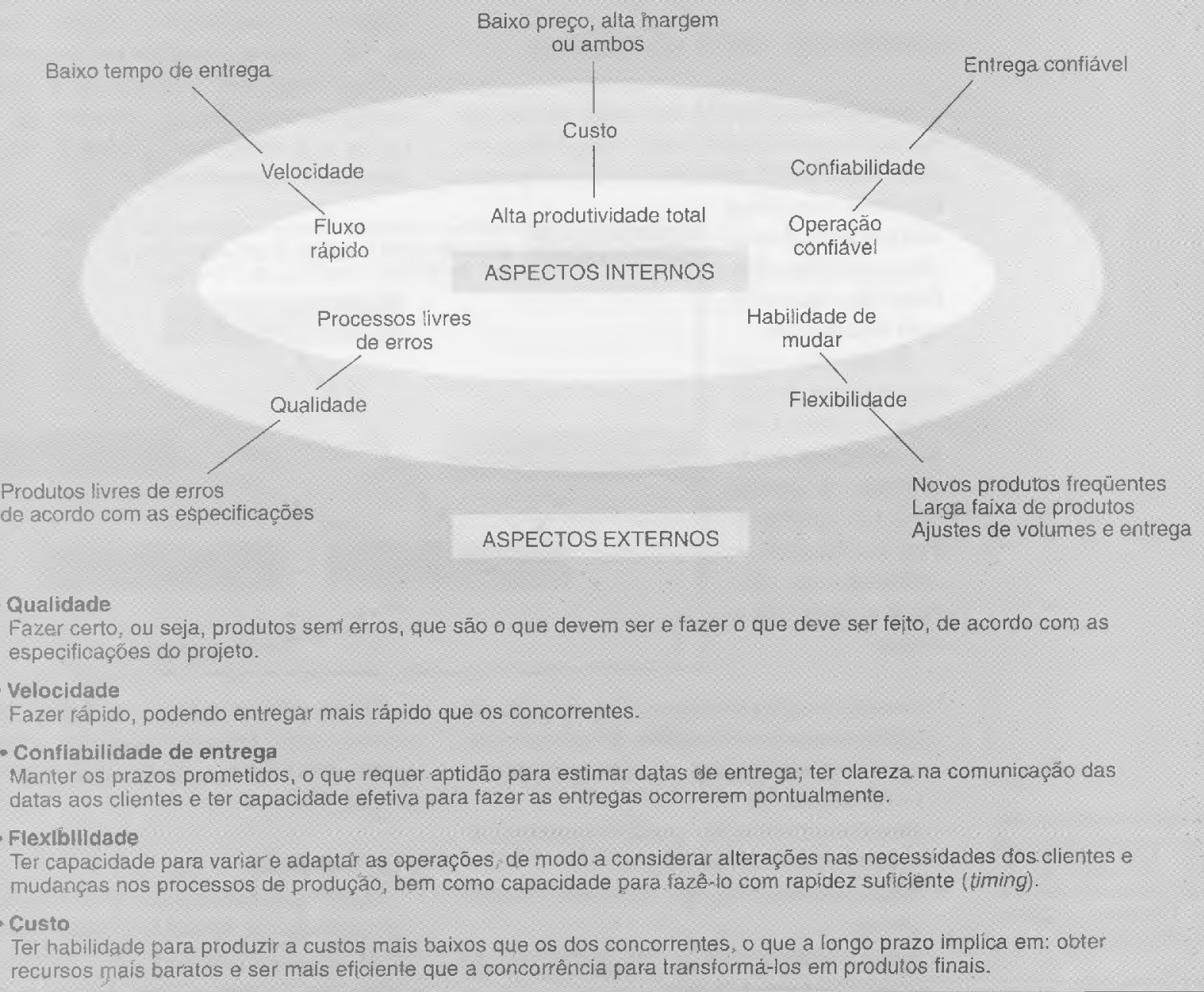




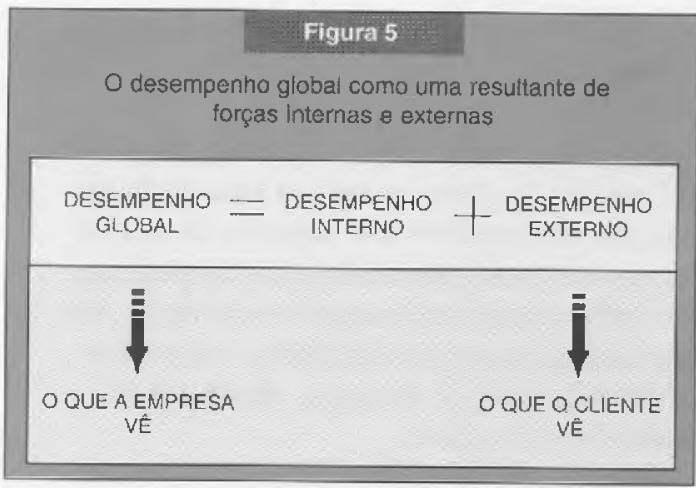

De fato, encontrar um ponto em que todos os objetivos sejam maximizados é virtualmente impossível, sendo normal que melhorias ou ênfase em um aspecto acabem sendo "pagas" com algum sacrifício de desempenho em outros.?

A arte está em encontrar a harmonia entre todos os aspectos, ou seja, encontrar o mix ideal, que permita à manufatura o máximo de colaboração na consecução das metas estratégicas dos negócios.

\section{NORMAS NBR 19000 X MANUFATURA}

A implantação de um sistema de garantia da qualidade, como o sugerido pela série NBR 19000, influencia o desempenho de uma empresa através de todos os cinco grandes objetivos da manufatura analisados.

À medida que sua ênfase é voltada à qualidade do produto e do processo, a aplicação dos postulados da norma ao ambiente de produção possibilita obter:

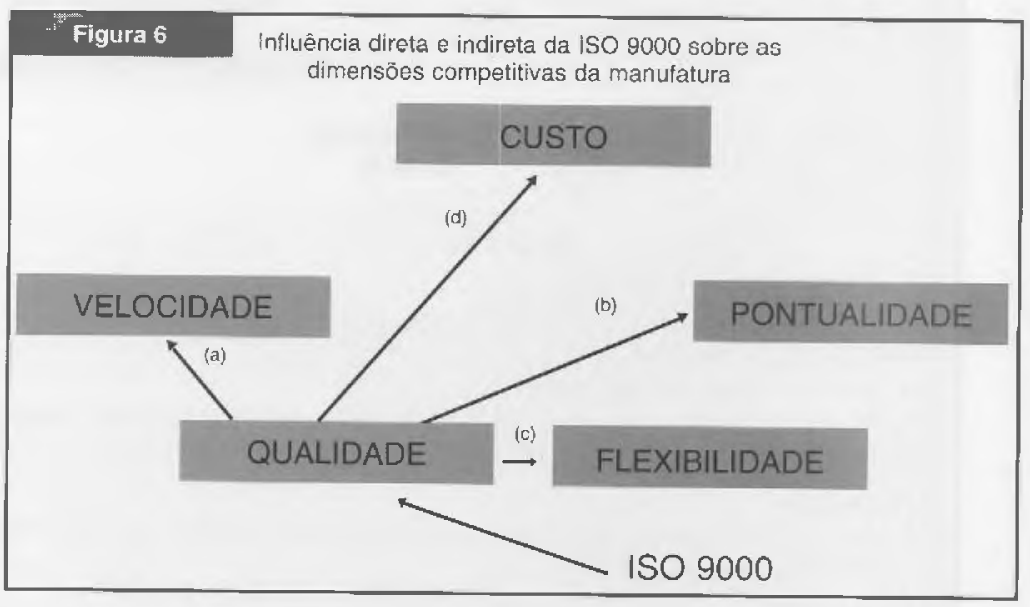

- maior conformidade dos produtos quanto às especificaçōes de fabricação;

7. SKINNER, W. Manufacturing - missing link in corporate strategy. In: GARVIN, D. Operations strategy: text and cases, Englewood Cliffs: Prentice-Hall, 1992

\section{SLACK, N. Op. cit.}

- maior eficiência na utilizaçăo dos recursos produtivos.

Existe, assim, um relacionamento direto da aplicação da norma ISO 9000 com a dimensāo de qualidade, bern como seus desdobramentos em relação às demais dimensões de competitividade da manufatura. Isto está ilustrado na figura 6.

A influência direta ou indireta da norma ISO 9000 pode ser descrita em função das cinco dimensões ou objetivos de competitividade da manufatura.

\section{Velocidade}

Maior velocidade de processamento, como resultado de menor tempo perdido para identificação e tratamento de "nãoconformidades" e de menor necessidade de improvisações para controle do processo devido à padronização dos procedimentos operacionais.

Se considerarmos que o tempo de desenvolvimento de novos produtos é parte importante do ciclo de produção (ver figura 6.1), mas ocorrendo em paralelo, podemos observar que são as funções de compras, manufatura, distribuição e marketing que limitam a chegada de novos produtos ao mercado. ${ }^{8}$
Desse modo, ganhos no tempo de manufatura significam produtos colocados mais rapidamente à disposição dos consumidores.

\section{Pontualidade}

Maior pontualidade de entregas, uma vez que são eliminadas grande parte das incertezas associadas ao "antigo" processo, tais como variabilidade das perdas relação ao seu projeto; 


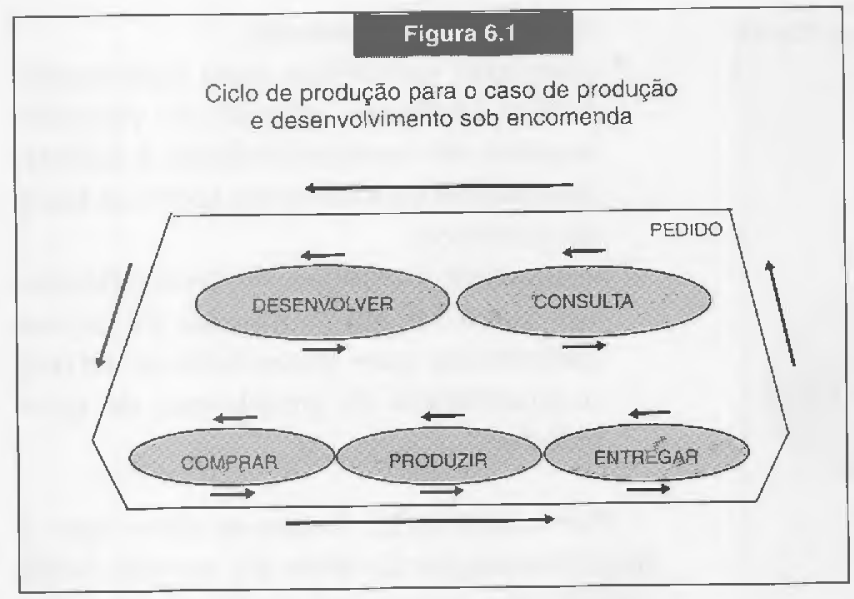

dutividade, segundo o modelo proposto por Gold, a conformidade com a série NBR 19000 pode significar ganhos substanciais, tais como (ver figura 7):

- aumento da relação lucro/ saídas, como resultado da diminuiçăo do custo médio de produção, à medida que a fábrica passa a trabalhar com menores níveis de perda;

- aumento da relação saídas/

e falta de padronização de procedimentos operacionais e são capitalizadas as vantagens correspondentes ao melhor conhecimento do processo de produção.

\section{Flexibilidade}

Considerando o sistema como um todo, podemos ter maior flexibilidade à introdução e produção de novos produtos, ou modificações nos existentes, como resultado da maior velocidade de resposta que possui um sistema "enxuto", com menores tempos "mortos" e poucas ocorrências de "não-conformidades".

De qualquer maneira, isso pode nāo ser suficiente se a empresa vier a competir com base em outros tipos de flexibilidade ou mesmo quando a flexibilidade de novos produtos for vital.

A ISO 9000 contribui para a maior flexibilidade dos recursos, uma vez que facilita a rápida adaptação das pessoas às operaçốes (ou vice-versa), dado que pressupõe forte padronização e documentação, que, por sua vez, facilita as atividades de treinamento.

Fica claro, portanto, que a adoção da série de normas ISO 9000 não possui grandes implicações positivas diretas ou indiretas nesse quesito.

\section{Custo}

Permite à empresa menores custos de produção, à medida quc possibilita operar em níveis menores de refugo e retrabalho, além de menores custos posteriores com relação à garantia.

Adicionalmente, como resultado da relação direta entre qualidade e pro- investimento total, como resultado da elevação do nível de utilização da capacidade instalada, para produção de "bons produtos".

Ainda com relação à qualidade, podemos utilizar a classificação adotada por Garvin, ${ }^{10}$ que define oito dimensões para aná-

lise e ação ge-

rencial, considerando a qualidade inerente ao produto.

A figura 8 nos fornece um quadro mais claro correspondente às influências diretas da implementação de procedimentos em conformidade com a série NBR 19000 , nas dimensões da qualidade dos produtos.

\section{CONCLUSÕES}

Se observar-mos os modelos propostos por Garvin e Slack e os pressupostos contidos na série NBR 19000 (ou NBR 19001, que é a mais completa), podemos notar, não apenas a complementaridade das definições ali contidas, mas também que na essência todos apresentam as mesmas idéias vistas sob um prisma diferente.

Desse modo, sumarizando o que foi colocado, podemos considerar dois importantes grupos de razões para a adoção
9. GOLD, B. Technology, productivity and economic analysis. The internationa! Journal of Management Sciences, v.1, n. 1, 1973.

10. GARVIN, D. A. Op. cit. 


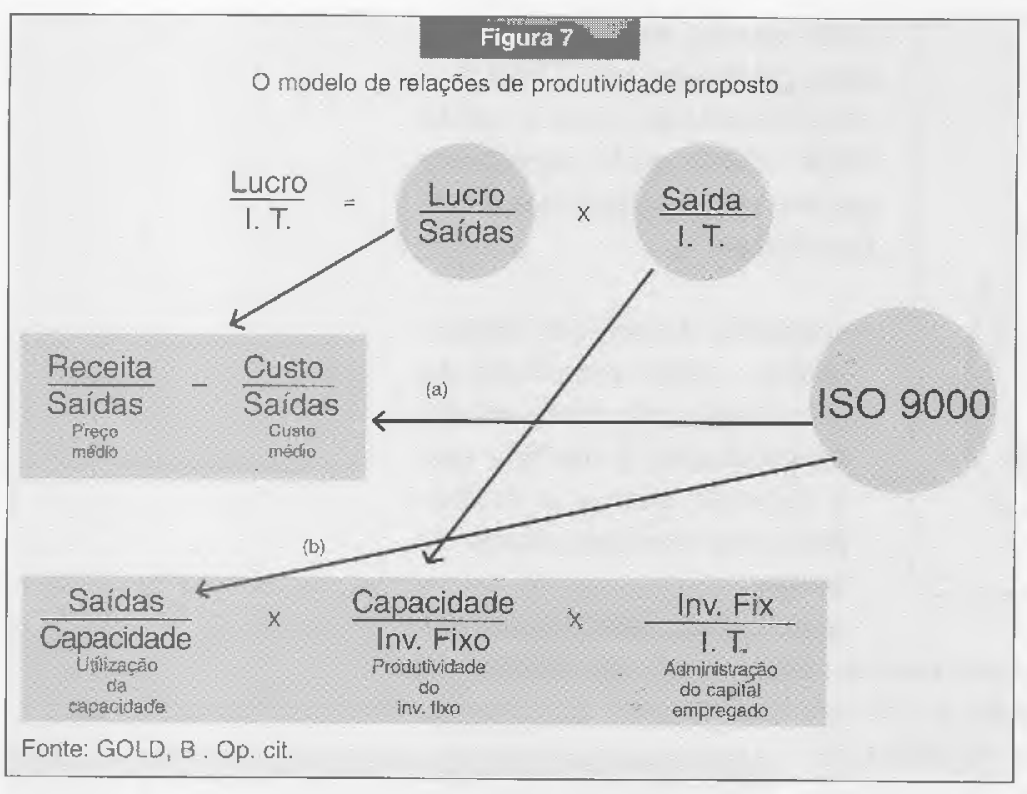

de procedimentos em conformidade com a série de normas NBR 19000:

- razões de mercado (externas): para manter ou conquistar a confiança de parceiros internacionais, superar barreiras comerciais, ou mesmo formar uma imagem positiva.

- razões de eficiência técnica (internas): aumentar a produtividade na utilização dos fatores de produção;

* assegurar conformidade às especificações;

* assegurar desempenho adequado ou em conformidade com o que foi projetado;

* assegurar consistência na obtenção da confiabilidade dos produtos obtidos;

* assegurar consistência na confiabilidade dos processos de produção utilizados;

* assegurar relacionamento adequado, formal e conhe- cido com fornecedores;

* assegurar condições para aperfeiçoamento contínuo, através de procedimentos de rastreabilidade e identificaçãodos produtos em todas as fases do processo;

* assegurar a adoção de procedimentos para implementação de ações corretivas que possibilitem evitar a recorrência de problemas de qualidade.

Por outro lado, torna-se claro que a implementação da série de normas NBR 19000 não deve ser vista como uma panacéia, que vai resolver todos os problemas.

Pelo contrário, podemos observar que existem vários aspectos ligados ao desempenho da manufatura que não sofrem sua influência.

A figura 9 ilustra, de maneira bastante clara, a influência indireta dos postulados da série de normas ISO 9000 nos aspectos competitivos externos de uma estratégia de manufatura.

Do mesmo modo, por via de conseqüência, quando pensamos estrategicamente nas grandes dimensöes de competitividade de uma empresa, seja preço, qualidade ou prazo de entrega.

Ainda considcrando essas dimensões de competitividade, em função do tipo de negócio explorado pela empresa, pode ou não ser importante sua adoção, uma vez

Figura 8

A ISO $9000 \times$ objetivos de desempenho da manufatura dimensóes da qualidade dos produtos

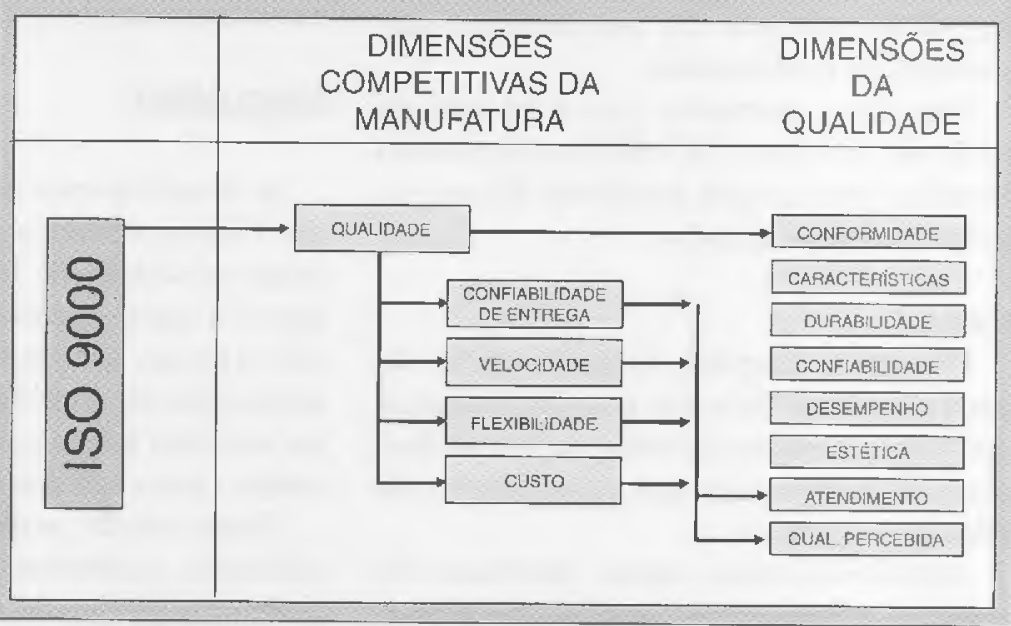




\section{Figura 9}

Infłuência direta e indireta nos aspectos internos e externos da manufatura

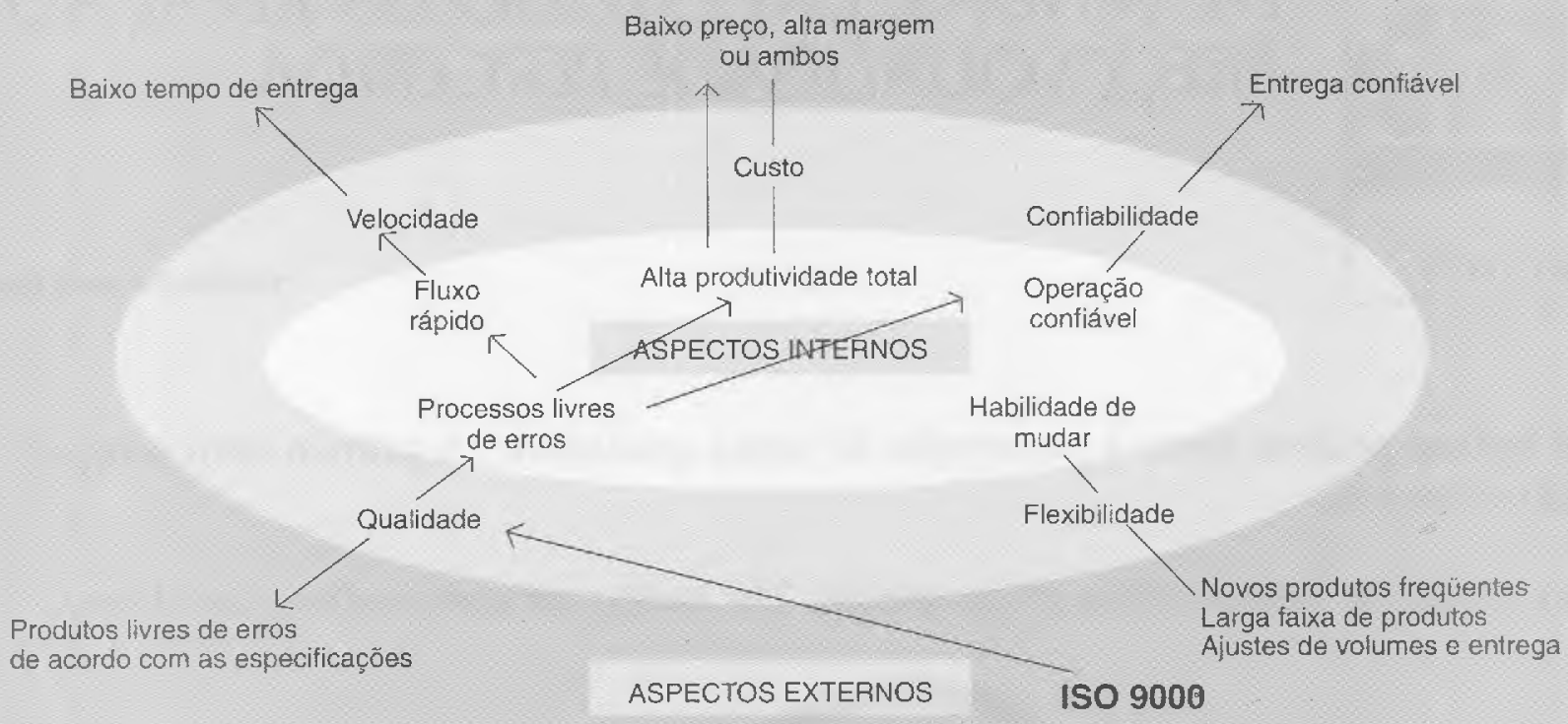

que nem todas as dimensões de competitividade são por ela atingidas.

Portanto, retiradas as evidentes implicações ou razões de mercado envolvidas, a adoção da série de normas NBR 19000 pode ser vista como sendo um embrião mais pragmático (à medida que possibilita resultados a curto e médio prazos) da implantação de um programa de ação competitiva considerando todos os fatores que influenciam os negócios da empresa como um todo.

Como possui um elenco de resultados práticos palpáveis e facilmente visualizáveis, pode ser encarada também como sendo uma "cunha de penetraçăo" para implantação do conceito de qualidade em. um contexto mais abrangente.

\section{BIBLIOGRAFIA SUPLEMENTAR}

CROSBY, P. B. Qualidade - falando sério. São Paulo: McGraw-Hill, 1990.

HLLL, T. Manufacturing strategy: text and cases. New York: Irwin, 1993.

HAYES, R., WHEELWRIGHT, S.C. Restoring our competitive edge. New York: Wiley, 1984.

Competing through manufacturing. In: GARVIN, D. Operations strategy: text and cases, Englewood Cliffs: Prentice-Hall, 1992.

MUSCAT, A.R.N. O conceito de produtividade. São Paulo: Escola Politécnica da USP (paper), 1990. 